\title{
Chronological Changes in Teacher-student Relationship: A Comparative Review of Traditional and New Periods
}

\author{
Yuezhi Yu ${ }^{1, \text { a, * }}$ \\ ${ }^{1}$ University of California, Santa Barbara, Goleta, CA, USA \\ *Corresponding author.Email: “yuezhi@ucsb.edu
}

\begin{abstract}
This review aims to analyze the changes in teacher-student relationships over time through previous researches. Past and recent research addressed teacher-student relationships from different views. There has been an alternation of the important components of teacher-student relationships, such as the teacher's authority and parental involvement from time to time. A suggestive area of future researches is proposed.
\end{abstract}

Keywords: Teacher-student relationships, Chronological changes, Teacher's authority, Parental involvement.

\section{INTRODUCTION}

Teachers and students face problems at school that some difficulties could impede them from performing better in the education area. The demand for the teacher is increasing, and the supply is not enough to meet the needs in school [1]. Students also have similar dilemmas like high dropout rate, which has been an important issue considered by each country. The possible reasons that generate such issues vary. Interpersonal relationship affects human beings in different ways both in mental and behaviors [2]. In the realm of education, teachers and students are the main components in school who have to interact with each other frequently. The teacher-student relationship (TSR) is an interpersonal relationship is influencing teacher and student a lot [3]. This variable can be one of the factors that cause those issues to challenge teachers, students, schools, and the whole education field.

Even though there have been numerous studies researched on the effect of TSR and its importance in student learning, researchers scarcely discussed TSR changes in the past decades. In the current article, the chronological changes of the teacher-student relationship will be discussed by comparing earlier and present studies regarding the authority of teacher and family involvement. The changes should be further discussed and studies for several reasons listed below.

\section{CONCEPT OF TSR}

\subsection{Definition and measurement}

The teacher-student relationship has been viewed from different perspectives, and the attachment theory is one of the perspectives that raise questions for researchers to explore more about TSR. The attachment theory argues that people are born with caregiving behaviors and the ability to seek comfort and attach to close people, especially parents, for basic needs [4]. However, people other than parents can also provide attachments. For example, the child may earn security from teachers at school even though attachment is not a long-term bond formed between teacher and students. The base of the theory initiated the conceptualization and operationalization of TSR [5]. Thus, we generally see TSR as an attachment-based interpersonal relationship.

According to Hamre and Pianta [6], who examined TSR by Student-Teacher Relationship Scale (STRS), a teacher's report of their relationships is divided into closeness, dependency, and conflict. STRS is the most worldwide used and valid scale for measuring teacherstudent relationship quality (TSRQ). The student's perspective of TSRQ was tested due to its importance and the lack of student perspective in STRS [7]. In this study, Wu et al. measure TSR by student ratings, teacher ratings, and peer evaluations. The relationship is strongly correlated with school behaviors and performance. High 
conflicts and over-dependency between teacher and student imply a negative relationship. Covariates such as gender and cognitive ability differ in the result.

Hagenauer and Volet [8] summarized two broad dimensions of TSR through previous studies, effective and support dimensions. In the affective dimension, teachers should give enough care for students for a positive and effective relationship that student will feel secure from it. As for the support dimension, the teacher should utilize TSR to support the student in their academic success. As an antecedent, teacher-student interaction is the basis of TSR, that the occurrence and quality of interactions are all relevant to the quality of TSR [8].

\subsection{Outcome variables of TSR}

Firstly, teacher's emotional status fluctuated with their closeness with students, and TSR affects their wellbeing in some way [9]. They could feel anxious or appear negative emotions when the relationship with students is reported as more distant [10]. Moreover, the teacher would have higher personal accomplishment when their closeness with students is more compared to conflicts [11]. TSR as a possible reason for these variables that can impact teachers can change over time due to intrinsic and extrinsic factors. Observing the variables and phenomena varied through decades can help teachers improve their personal status and ameliorate the lack of supply in teachers.

Secondly, the interpersonal relationship between teacher and students impacted not only teachers' life and personal status but also impacted students'. Teacher's well-being and student's well-being were associated with each other positively [12], and teacher's well-being draws more people's attention because it could subsequently influence student's mental health. Researchers studied different variables to improve students' performance and behaviors in school and higher the quality of education. Decreased support from teachers and classmates led to more mental health issues among students [13].

Furthermore, positive TSR was linked with higher student competence, anatomy, and the need for satisfaction [14]. Students' motivation and achievement may show better with positive TSR since they would not disgust learning due to negative relationships with the teacher. By enhancing TSR, students and teachers reported that increases in student academic outcome competence also increase their prosocial behaviors [15]. TSR could be modified differently by some outer factors such as parental involvement, which may alter students' attitudes toward learning and schooling.

\section{CHRONOLOGICAL CHANGES OF TSR}

Previous studies have shown that TSR plays a significant part in student learning and teacher's career life. By digging deeper into its overtime development and transformation, some problems that emerged might be solved easier.

\subsection{The authority and power of teacher}

Power and authority are usually defined as the capability of controlling force from leadership that they have the right to make decisions and demand others to do the requested things. In education, power and authority are not mentioned a lot since equality between teacher and student is emphasized more importantly. However, teachers and students should not deny the existence of power in teaching. Rather they should understand it fully to resolve issues that appeared in their relationships [16]. Strong power can cause conflicts, but it can also result in some beneficial effects that it is an indispensable part of the teacher-student relationship. Conflicts is one of the scales tested in STRS that is one significant part of TSR.

However, there has been a trend of declining teacher's power and authority. Over the last two decades, people's discussion on the diminishing of authority in teachers has become less because such questions are found earlier than we thought. Coercion and power from teachers were associated with student's negative attitudes and often cause conflicts [17]. Researchers began to investigate the negative effects of undue power and coercion teachers put on students and started to change to the dilemma. Additionally, due to several reasons, such as less support from the school department and the change of belief of students and parents, teachers feel that their power and authority have been diminished over time [18]. In the study, teachers reported that students no longer feared them, and their leadership position was not stable anymore even though students still believed that they are under the control of the teacher's power. In a more recent article, Teachers are losing their dominant role, especially from their own perspectives, because of the change of instructional way and program design [19]. The power and authority of teachers seem not to be considered recently, and a more friendly and equal relationship between teacher and student is presented and emphasized in school for student's wellbeing and learning attitude.

The question here for the teacher is that whether the decreasing of power and authority in the classroom is conducive to make a supportive classroom environment and positive TSR. Alderman and Green [20] discussed applying the social power model in teaching regarding the techniques for using power. The model contains four types of power which are coercion, manipulation, expertness, and likability. These four social powers, if wisely used by teachers, will generate positive effects. 
For an appropriate classroom setting, democratic and authoritative management are both needed to maintain equality and guide students to behave correctly when the classroom is mixed with different gender and races [21]. Consequently, teachers should always pay attention to student's voices, but they should also maintain their power and authority in front of students to prevent misbehaviors. The relationship between them would not be harmed if teachers handle their authority and power with proper means, and pedagogies, in this case, can be further discussed.

\subsection{Parental involvement}

There are a lot of literatures discussed and studies about parent involvement in schools and education. The parent can involve in their children's life in school through many ways, such as attending school activities, assisting children's learning processes, and so on [22]. We cannot overlook the importance of parent involvement in school that their participation is a huge part of student's learning. Nevertheless, earlier studies about parent involvement were to limit its manner of involvement and the effect on student's motivation and academic achievement [23, 24]. Overall, there is a positive relationship between parent involvement and student's academic performance. It is hard to find studies in earlier decades that discussed the relationship between parent involvement and TSR. The relationship between parent and children, parent and teacher, may all affect TSR.

The parent-teacher relationship now raises awareness as a teacher-student relationship, and researchers began to explore more about it. Parents participate in children's education more and more because they become aware of their role in education that their aspirations, advice, and decisions are crucial to children's plans [25]. The parentteacher relationship was connected with children's social development and closeness with the teacher [26]. In TSR, students and teachers would have less conflict when related to high parent involvement, and regression was found in low-income students [27]. Parent and family involvement has a positive effect on TSR, and usually, vice versa. Additionally, the collaboration between parents and teachers guides students toward positive attitudes and promotes better TSR [28]. Thus, parents are encouraged to participate more in children's academic and school life to be a leading factor to motivate and help their children succeed.

\section{IMPLICATIONS AND FUTURE DIRECTIONS}

Future research on changes of the specific features of TSR might extend the explanations of the understanding of TSR over time. People should see TSR as a dynamic variable that differs with changes in society and people's beliefs rather than a static one that stays the same. Developing more on the changes in the relationships between TSR and other variables would also be helpful. In addition, the measurement of TSR differs in studies that even though most of them used STRS, some used other questionnaires, and the participants vary in teacher, student, peer, and parents [7]. It is necessary to see if closeness, conflict, and dependency are still three things that define TSR nowadays or the scale is altered due to the changes that happened on it. Therefore, the measurement needs further examination and investigation.

A heuristic lesson here for people with different roles in education is to realize the trend of TSR and modify opinions and behaviors to adjust to the current classroom environment. Teachers should have a correct orientation on how to identify their role and the importance of student's role in class now. Teachers' education can be broader, including how to let students respect teachers and obey their instructions because the diminishing of the teacher's power and authority becomes a problem. For students, they have to cope with their relationship with teachers. The teacher's guidance is helpful for them in most situations. Students' respect and obedience in a certain situation will benefit both of them and the whole class.

Furthermore, parent and family involvement is indeed necessary for students to perform better at school, but too much involvement may lead to negative effects. The student's test anxiety was correlated with parent over-involvement that students would receive more pressure from parents when they engaged a lot in their academic life [29]. The goal for high-quality TSR and parent involvement is for student's and teacher's wellbeing. It will be no longer effective to advocate for parent involvement if parents provide too much stress on their children since the effect is already negative. The parent should guide children and support them, and the children themselves will choose their own path [25].

\section{CONCLUSIONS}

This paper reviews the basic concept of TSR and its trend and changes over decades. In summary, the paper shows that previous studies focused more on the relationship between TSR and other variables while overlooking TSR changes based on changes in pedagogy and attitudes toward education. There is a shift in teacher's authority and power in comparison to traditional and current views. Parental involvement is a big part of schooling that raises concerns on the relationship with TSR, and the parent-teacher relationship becomes another key research object in education. These findings could be good references for those who plan to contribute to future TSR researches, and it could be helpful to teachers, student, and parent to 
learn clearly about the current status and what they should do.

\section{REFERENCES}

[1] L. Sutcher, L. Darling-Hammond, D. Carver-Thomas, Understanding teacher shortages: An analysis of teacher supply and demand in the United States. Education Policy Analysis Archives, 2019, 27. http://dx.doi.org/10.14507/epaa.27.3696

[2] M. Okada, T. Suzue, F. Jitsunari, Association between interpersonal relationship among highschool students and mental health. Environmental health and Preventive Medicine, 2010, pp. 57-62. https://doi.org/10.1007/s12199-009-0108-7

[3] D. Evans, R. Butterworth, G.U. Law, Understanding associations between perceptions of student behaviour, conflict representations in the teacherstudent relationship and teachers' emotional experiences. Teaching and Teacher Education, 2019, pp. 55-68. https://doi.org/10.1016/j.tate.2019.03.008

[4] N.L. Collins, M.B. Ford, Responding to the needs of others: The caregiving behavioral system in intimate relationships. Journal of Social and Personal Relationships, 2010, pp. 235-244. https://doi.org/ 10.1177/0265407509360907

[5] K. Verschueren, H.M.Y. Koomen, Teacher-child relationships from an attachment perspective. Attachment \& Human Development, 2012, pp. 205-211. https://doi.org/10.1080/14616734.2012.672260

[6] B.K. Hamre, B.C. Pianta, Early Teacher-Child Relationships and the Trajectory of Children's School Outcomes through Eighth Grade. Child Development, 2001, pp. 625-638. https://doi.org/10.1111/1467-8624.00301

[7] J.-Y. Wu, J.N. Hughes, O.-M. Kwok, Teacherstudent relationship quality type in elementary grades: Effects on trajectories for achievement and engagement. Journal of School Psychology, 2010, pp. $357-387$. https://doi.org/10.1016/j.jsp.2010.06.004

[8] G. Hagenauer, S.E. Volet, Teacher-student relationship at university: an important yet underresearched field. Oxford Review of Education, 2014, pp. 370-388. https://doi.org/10.1080/03054985.2014.921613

[9] J.L. Spilt, H.N.Y. Koomen, J.T. Thijs, Teacher Wellbeing: The Importance of Teacher-Student Relationships. Educ Psychol Rev, 2011, pp. 457477. https://doi.org/10.1007/s10648-011-9170-y
[10] G. Hagenauer, T. Hascher, S.E. Volet, Teacher emotions in the classroom: associations with students' engagement, classroom discipline and the interpersonal teacher-student relationship. European Journal of Psychology of Education, 2015, pp. 385-403. https://doi.org/10.1007/s10212-015-0250-0

[11] C.M. Corbin, P. Alamos, A.E. Lowenstein, J.T. Downer, J.L. Brown, The role of teacher-student relationships in predicting teachers' personal accomplishment and emotional exhaustion. Journal of School Psychology, 2019, pp. 1-12. https://doi.org/10.1016/j.jsp.2019.10.001

[12] S. Harding, R. Morris, D. Gunnell, T. Ford, W. Hollingworth, K. Tilling, R. Evans, S. Bell, J. Grey, R. Brockman, R. Campbell, R. Araya, S. Murphy, J. Kidger, Is teachers' mental health and wellbeing associated with students' mental health and wellbeing? Journal of affective disorders, 2019, pp. 180-187. https://doi.org/10.1016/j.jad.2018.08.080

[13] D.J. Wit, K. Karioja, B.J. Rye, M. Shain, Perceptions of declining classmate and teacher support following the transition to high school: Potential correlates of increasing student mental health difficulties. Psychology in the Schools, 2011, pp. 556-572. https://doi.org/10.1002/pits.20576

[14] O. Bakadorova, D. Raufelder, The essential role of the teacher-student relationship in students' need satisfaction during adolescence. Journal of Applied Developmental Psychology, 2018, pp. 57-65. https://doi.org/10.1016/j.appdev.2018.08.004

[15] C. Longobardi, M. Settanni, S. Lin, M.A. Fabris, Student-teacher relationship quality and prosocial behaviour: The mediating role of academic achievement and a positive attitude towards school. British Journal of Educational Psychology, 2020, pp. 547-562. https://doi.org/10.1111/bjep.12378

[16] M. McNay, Power and Authority in Teacher Education. The Educational Forum, 2004, pp. 72 81. https://doi.org/10.1080/00131720308984605

[17] D.W. Jamieson, K.W. Thomas, Power and Conflict in the Student-Teacher Relationship. The Journal of Applied Behavioral Science, 1974, pp. 321-336. https://doi.org/10.1177/002188637401000304

[18] D.J. Cothran, C.D. \& Ennis, Students' and teachers' perceptions of conflict and power. Teaching and Teacher Education, 1977, pp. 541-553. https://doi.org/10.1016/s0742-051x(97)85542-4

[19] M. Klein, Shifts in power and authority in an elementary inclusion program: A case study, 
ProQuest LLC. 789 East Eisenhower Parkway, PO Box 1346, Ann Arbor, MI 48106, 2009. Web site: http://www.proquest.com/enUS/products/dissertations/individuals.shtml

[20] G.L. Alderman, S.K. Green, Social Powers and Effective Classroom Management. Intervention in School and Clinic, 2011, pp. 39-44. https://doi.org/10.1177/1053451211406543

[21] E.J. Graham, Authority or Democracy? Integrating Two Perspectives on Equitable Classroom Management in Urban Schools. The Urban Review, 2017, pp. 493-515. https://doi.org/10.1007/s11256-017-0443-8

[22] K. Cotton, K.R. Wikelund, Parent involvement in education. School Improvement Research Series, 1989, pp. 17-23.

[23] E.H. Sui-Chu, J.D. Willms, Effects of Parental Involvement on Eighth-Grade Achievement. Sociology of Education, 1996, pp. 126. https://doi.org/10.2307/2112802

[24] X. Fan, Parental Involvement and Students' Academic Achievement: A Growth Modeling Analysis. The Journal of Experimental Education, 2001, pp. 27-61. https://doi.org/10.1080/00220970109599497

[25] M. Ule, A. Živoder, M. Du Bois-Reymond, 'Simply the best for my children': patterns of parental involvement in education. International Journal of Qualitative Studies in Education, 2015, pp. 329-348. https://doi.org/10.1080/09518398.2014.987852

[26] Z.N. Serpell, A.J. Mashburn, Family-School Connectedness and Children's Early Social Development. Social Development, 2011, pp. 21$46 . \quad$ https://doi.org/10.1111/j.14679507.2011.00623.x

[27] A.J. Wyrick, K.M. Rudasill, Parent Involvement as a Predictor of Teacher-Child Relationship Quality in Third Grade. Early Education and Development, 2009, pp. 845-864. https://doi.org/10.1080/10409280802582803

[28] V. Krane, T. Klevan, There are three of us: parents' experiences of the importance of teacher-student relationships and parental involvement in upper secondary school. International Journal of Adolescence and Youth, 2018, pp. 74-84. https://doi.org/10.1080/02673843.2018.1464482

[29] E. Shadach, O. Ganor-Miller, The role of perceived parental over-involvement in student test anxiety. European Journal of Psychology of Education, 2012, pp. 585-596. https://doi.org/10.1007/s10212-012-0131-8 